\title{
Der andere Autor im eigenen Werk. Mediatisierte Autorschaft bei Mateo Alemán und Miguel de Cervantes.
}

\section{Autorschaft und mimetisches Begehren: Alemán, Cervantes und die Funktion des Mediatoren}

Auf ihrer Suche nach einem >Ursprung « des modernen Romans ist die Forschung immer wieder auf Cervantes' Don Quijote gestoßen ${ }^{1}$, was nicht zuletzt der deutschen Romantik geschuldet ist. Friedrich Schlegel bestimmte in einer ans Tautologische grenzenden Definition nicht nur den Roman als »romantisches Buch « und eigentliche Gattung der Moderne ${ }^{2}$, sondern erkannte im Don Quijote auch ein besonders gelungenes Beispiel für die von ihm angestrebte »progressive Universalpoesie «. ${ }^{3}$ Das Potential zum unendlichen Progress macht er dabei im selbstreflexiven Charakter des Werkes aus, dessen erster Teil im zweiten Teil zur »Hauptperson « werde $^{4}$, eine selbstreflexive Schließung, die den Roman ebenso zum autonomen Werk wie zur tiefgründig symbolischen Reflexionsform mache. Grundlage solcher Werkautonomie bildet im Denken der Romantik eine ebenso ausgeprägte Autonomie des Autors, der als Genie einzigartig und unabhängig von kontextuellen Einflüssen ist: »Cervantes geht ganz seinen Weg für sich und ist durchaus und in sich selbst verständlich; er hat gar keine Umgebung «, heißt es dementsprechend an anderer Stelle der literarischen Notizen Schlegels. ${ }^{5}$

Die Modernität des Don Quijote ist in dieser romantischen Lesart nicht zu trennen von einer auf Autonomie ausgerichteten Autorschaftskonzeption,

\footnotetext{
Vgl. Daniel-Henri Pageaux, Naissances du roman, Paris: Klincksieck 1995, S. 59-63.

»Wie unsre Dichtkunst mit dem Roman, so fing die der Griechen mit dem Epos an und löste sich wieder darin auf. Nur mit dem Unterschiede, daß das Romantische nicht sowohl eine Gattung ist als ein Element der Poesie, das mehr oder minder herrschen und zurücktreten, aber nie ganz fehlen darf. [...] Ein Roman ist ein romantisches Buch« (Friedrich Schlegel, »Brief über den Roman«, in: Kritische Schriften und Fragmente, hg. v. Ernst Behler und Hans Eichner, Paderborn: Schöningh 1988, Bd. 2, S. 212f.).

3 Deren Programm formuliert Schlegel insbesondere im 116. Athenäums-Fragment. Zur romantischen Lektüre des Don Quijote vgl. Sebastian Neumeister, »Der romantische Don Quijote«, in: Christoph Strosetzki (Hg.): Miguel de Cervantes' "Don Quijote«. Explizite und implizite Diskurse im »Don Quijote«, Berlin: Erich Schmidt Verlag 2005, S. 301-314; zur Cervantes-Rezeption in der deutschen Romantik insgesamt Werner Brüggemann, Cervantes und die Figur des Don Quijote in Kunstanschauung und Dichtung der deutschen Romantik, Münster: Aschendorff 1958.

4 »Die Hauptperson in II D(on) Q(uixote) ist der erste Theil. Es ist durchgängig Reflexion des Werks auf sich selbst« (Friedrich Schlegel, Kritische Schriften und Fragmente, Bd. V, Fragment 185, S. 253).

5 Ebd., Fragment 241, S. 255.
} 
deren Durchsetzung eine der nicht gering zu veranschlagenden Leistungen der literarischen Anthropologie seit dem späten 18. Jahrhundert war, die gegen eine lange Tradition von Regelpoetik und Verpflichtung auf imitatio die Schaffung von >Originalen $<$ unter Verweis auf das Vorbild der Natur zu einem Prinzip der Poesis machte. Edward Young war einer der ersten, der in seinen programmatischen Ausführungen zu den Conjectures on Original Composition (1759) Originalität aus der Natur abzuleiten versuchte und damit die imaginäre Denkfigur einer selbstgenetischen Autorschaft begründete, welche die europäische Genieästhetik insgesamt durchzieht. ${ }^{6}$ Die Tatsache, dass Harold Bloom Cervantes' Werk vor einigen Jahren in die Ahnenreihe der exemplary creative minds aufnahm, zeigt, dass die Stilisierung des Don Quijote zu einem spezifisch modernen und genau wegen seiner Einzigartigkeit maßgebenden >Original nach wie vor anhält. ${ }^{7}$ Diese Wirksamkeit einer genieästhetischen Stilisierung des Textes zum selbstgenetischen Original ist dabei umso erstaunlicher, als sie seinen ganz offensichtlich hypertextuellen Charakter ignorieren muss und den konstitutiven Bezug auf ein schon vorausliegendes Schreibmodell, die novela de caballería. ${ }^{8}$ Mimesis ist konstitutiv im Don Quijote, und wenn man sie nicht nur gattungspoetisch ernst nimmt, als ein Phänomen der Transtextualität im Sinne Gérard Genettes, sondern auch anthropologisch, so kann man zur Ansicht gelangen, dass der Don Quijote nicht nur kein geniales Original im (trivial-)romantischen Sinne ist, sondern ein geradezu antiromantisches Werk. René Girard konnte den Roman deshalb in seiner Studie zu Mensonge romantique et vérité romanesque zum Ausgangspunkt nehmen, um der romantischen $>$ Lüge $<$ von der unmittelbaren Natur des Begehrens die \Wahrheit von der tragenden Rolle des Vermittlers im Prozess des Begehrens entgegenzusetzen, die Cervantes exemplarisch vorgeführt habe und deren Analyse ein Grundverdienst des modernen Romans sei. Girard weist dabei die romantische Vorstellung einer unabhängigen »Parthenogenese der Imagination « ${ }^{9}$ zurück und setzt der romantischen Illusion einer unmittelbaren Beziehung zwischen sujet désirant und objet desiré, die auch als Grundlage identifikatorischer Lektüre fungiert, die Theorie eines triangulären Begehrens entgegen, bei dem die Instanz des Mediatoren von

6 Zur Bedeutung der Vorstellung von Selbstschöpfung für ein spezifisch modernes Konzept von Autorschaft vgl. u. a. David E. Wellbery, »Kunst - Zeugung - Geburt. Überlegungen zu einer anthropologischen Grundfigur«, in: Christian Begemann/Ders. (Hg.), Kunst - Zeugung - Geburt. Theorien und Metaphern ästhetischer Produktion in der Neuzeit, Freiburg i. Br.: Rombach 2002, S. 9-36, sowie Christian Begemann, »Der Körper des Autors. Autorschaft als Zeugung und Geburt im diskursiven Feld der Genieästhetik«, in: Heinrich Detering (Hg.), Autorschaft. Positionen und Revisionen, Stuttgart/Weimar: Metzler 2002, S. 44-61.

7 Harold Bloom, Genius. A Mosaic of one Hundred Exemplary Creative Minds, New York: Warner Books 2002, S. 33-40.

8 Zur Hypertextualität des Don Quijote vgl. Gérard Genette, Palimpsestes. La littérature au second degré, Paris: Seuil 1982, S. 201-217.

9 Vgl. René Girard, Mensonge romantique et vérité romanesque. Préface inédite de l'auteur [1961], Paris: Grasset, 2001, S. 40. 
entscheidender Bedeutung ist. Mit Hilfe des Quijote und anderer Romane, denen er einen anthropologischen Mechanismus abliest, den er später in seinen religionssoziologischen Schriften weiter entfalten wird, kämpft Girard gegen einen modernen Verblendungszusammenhang an, den er in der Selbsttäuschung des Individualismus ausmacht, die zu einer Perpetuierung von Konkurrenzkampf und einer Spirale der Opfergewalt führt. Girard folgt dabei einer christlich-pessimistischen Anthropologie und sieht den Menschen als unterdeterminiertes Mangelwesen, das sein eigenes Seinsdefizit über die Aneignung der imaginierten Seinsfülle eines Modells auszugleichen versucht, womit dieses Modell als Mittler des Begehrens fungiert, das immer ein Begehren gemäß dem Anderen darstellt. ${ }^{10}$

Als Literaturwissenschaftler will ich im Folgenden nicht anthropologisch argumentieren, sondern Girards Modell des triangulären >metaphyischen< Begehrens, das er selbst als ein Leitthema des Don Quijote entdeckte, dazu nutzen, um es auf die Ebene des Autorschaftskonfliktes auszuweiten, von der sowohl die Werkproduktion von Mateo Alemán als auch die von Cervantes gekennzeichnet sind. Beide standen ja beim Versuch zur Modellierung einer Romanform, die den Bedürfnissen der literarischen Öffentlichkeit im Spanien um 1600 optimal entsprach, nicht nur in gegenseitiger Konkurrenz zueinander $^{11}$, sondern hatten auch jeweils mit einem pseudonymen Fremdautor um die Fortsetzung des je eigenen Werkes zu konkurrieren. Sowohl Alemán als auch Cervantes mussten erleben, dass eine Fortsetzung aus fremder Feder der eigenen Werkfortsetzung zuvorkam. Was in der Terminologie Genettes als Störung der autographen suite durch eine allographe continuation bezeichnet werden könnte ${ }^{12}$, lässt sich mit Girard auch als Fall eines mimetischen Konflikts beschreiben, wobei zwischen den Autor als sujet désirant und dem geschlossenen Werk als objet désiré ein anderer Autor als ein Rivale tritt, der insofern durch einen illusionären Wert ausgezeichnet ist, als er bereits die

${ }^{10} \mathrm{Zu}$ diesem anthropologischen Grundmodell Girards vgl. La violence et le sacré, Paris: Bernard Grasset 1972, S. 204f. Girard fasst Begehren also ontologisch-existentiell und nennt es deshalb auch meist désir métaphysique, um es vom rein sexuellen Begehrenstrieb zu unterscheiden.

11 Zum Konkurrenzverhältnis zwischen Alemán und Cervantes vgl. u. a. Francisco Márquez Villanueva, »La interacción Alemán-Cervantes«, in: Actas del II Coloquio Internacional de la Asociación de Cervantistas. Alcalá de Henares 6-9 noviembre 1989, Barcelona: Anthropos, 1991, S. 149-181, sowie Antonio Rey Hazas, »El Guzmán de Alfarache y las innovaciones de Cervantes«, in: Pedro M. Piñero Ramírez (Hg.), Atalayas del Guzmán de Alfarache. Seminario internacional sobre Mateo Alemán. IV Centenario de la publicación de Guzmán de Alfarache (1599-1999), Sevilla: Universidad de Sevilla 2002, S. 177-217. Dass die »Interaktion« der beiden Autoren, die Villanueva analysiert, dabei die Züge eines Konfliktes trägt, hat schon Edmond Cros zu Recht betont und daraus die Konsequenz gezogen, dem modernen >Realismus` eben keinen eindeutigen Ursprung zuzuweisen, sondern seine Genese vielmehr im kontradiktorischen und konfliktiven Dialog der beiden Romane als generierendes Moment anzusetzen (»Guzmán de Alfarache y los orígenes de la novela moderna«, in: Ebd., S. 167176).

12 Vgl. Genette, Palimpsestes, S. $282 \mathrm{f}$. 
Werkschließung erreicht hat. Alemán fungierte mit seinem Guzmán im Sinne Girards als Mediator Cervantes'. Dem einfachen Dreiecksverhältnis zwischen Subjekt (Cervantes), Mediator (Alemán) und Objekt des Begehrens (der ideale, abgeschlossene Roman) ist dabei jedoch ein doppelter mimetischer Konflikt eingeschrieben, den sowohl das Subjekt als auch der Mediator auszutragen hatten. Die externe Mediation zwischen Cervantes und Alemán umfasst also eine interne, als direkte Rivalität ausgetragene Mediation zwischen Alemán und dem pseudonymen Autoren, der als »Mateo Luján de Sayavedra" 1602 eine Fortsetzung veröffentlichte, und eine zweite, ebenso von direkter Rivalität gekennzeichnete interne Mediation ${ }^{13}$ zwischen Cervantes und $» F e r-$ nando de Avellaneda«, der ihm 1614 mit dem Segundo Tomo del ingenioso hidalgo Don Quixote de la Mancha zuvorkam (vgl. dazu das Schema in Abb. 1). Anders als Alemán konnte Cervantes sich bei der literarischen Verarbeitung seines eigenen mimetischen Konfliktes folglich an einem Konfliktmodell orientierten und von diesem profitieren. ${ }^{14}$

Zur Erläuterung dieser These werde ich mich darauf beschränken, die Strukturen dieses komplizierten, weil doppelt vermittelten und literarisch figurierten mimetischen Autorschaftskonfliktes herauszuarbeiten, der im Gegensatz zu motivlich-inhaltlichen Bezügen zwischen den jeweiligen Texten bisher von der Forschung noch kaum untersucht wurde. ${ }^{15}$ Dabei werde ich Girards anthropologisches Theoriemodell historisch zu konkretisieren versuchen und zeigen, dass der Konflikt zwischen Cervantes, Alemán und ihrem jeweiligen Autor-Rivalen nicht zuletzt von der spezifischen medialen Problematik von Autorschaft in der Frühzeit der >Gutenberggalaxis` geprägt ist.

13 Für die Unterscheidung zwischen interner und externer Mediation ist für Girard die Distanz zwischen Subjekt und Mediator entscheidend, nicht im physischen, sondern im spirituellen Sinne (Mensonge romantique, S. 31). Während Don Quijotes Verhältnis zu Amadís einer externen Mediation entspreche, stelle die Novelle vom curioso impertinente das Modell einer internen Mediation dar (S. 77).

14 Die seit über 300 Jahren nicht abreißenden Versuche, das Pseudonym Avellanedas möglichst eindeutig zu klären, haben dabei für die Frage nach der Funktion des anderen Autors im Quijote wenig beigetragen, wie schon Maurice Molho kritisch angemerkt hat (»Le sujet apocryphe ou l'art de gérer l'autre. Remarques sur le Don Quijotte d'Avellaneda«, in: Ders., Les figures de l'autre, Toulouse: Presse Universitaires du Mirail 1991, S. 39-47). Molhos Versuch, auf den Spuren Lacans im zweiten Teil des Quijote eine Interiorisierung der fonction de l'autre auszumachen, verdanke ich wichtige Anregungen, auch wenn ich selbst im Rahmen des Konfliktmodells Girards die Funktion des bzw. der anderen Autoren nicht (nur) psychoanalytisch fasse.

15 Neben der schon genannten Studie von Molho stellt lediglich die Arbeit von Benito Brancaforte, »Mateo Alemán y Miguel de Cervanates frente a los apócrifos«, in: Pedro M. Piñero Martínez (Hg.), Atalayas del Guzmán, Sevilla: Universidad de Sevilla, S. 219-240, eine bemerkenswerte Ausnahme dar. 


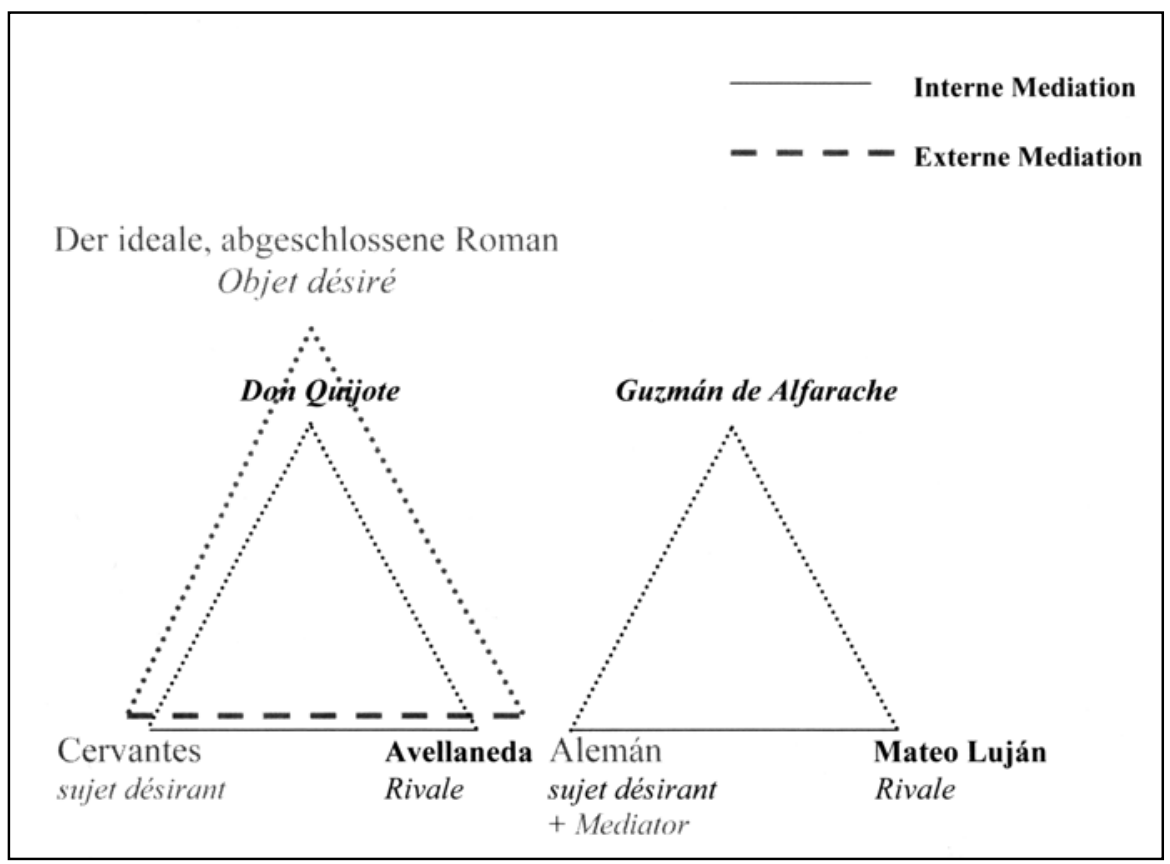

Abb. 1: Der mimetische Autorschaftskonflikt bei Mateo Alemán und Miguel de Cervantes

\section{Autorschaft im Zeitalter typographischer Vervielfältigung}

Die Umstellung der Textüberlieferung von der handschriftlichen auf eine typographisch-mechanische Vervielfältigung nach der Erfindung des Drucks mit beweglichen Lettern durch Gutenberg produzierte zwar vielleicht nicht den mentalen Paradigmenwechsel, den Medientheoretiker à la McLuhan behaupten ${ }^{16}$, hatte aber doch nicht zu unterschätzende Auswirkungen für die Organisation literarischer Kommunikation. Die trivialste, aber wahrscheinlich weitreichendste war die schlichte technische Beschleunigung der Vervielfältigung und die dadurch erzeugte Entwertung des materiellen Trägerstoffes. Der Besitz eines Manuskriptes war viel exklusiver als der eines gedruckten Buches, das mit zunehmender Perfektionierung der Drucktechnik immer erschwinglicher wurde. Die Darstellung der Bibliothek des Landjunkers Don Quijote in Cervantes Roman, die »más de cien cuerpos de libros grandes, muy bien encuadernados, y otros pequeños « $^{17}$ umfasst, wäre vor dem typographischen

16 Marshall McLuhan, The Gutenberg Galaxy, Toronto: U of Toronto P 1962.

17 Miguel de Cervantes, Don Quijote de la Mancha, hg. v. Francisco Rico, Barcelona: Crítica 1998, I, 6, S. 76f./73: »mehr als hundert Bände [cuerpos] großer gutgebundener Bücher nebst 
Zeitalter ein phantastischer und ganz unglaublicher Einfall gewesen und kein Realismus. Das Kapitel vom escrutinio de la biblioteca zeugt aber nicht nur vom Warencharakter des Buches Ende des 16. Jahrhunderts, sondern zeigt auch, dass es sich dabei um eine ideologisch gefährliche Ware handelte. Die gewachsene Schnelligkeit der Informationsverbreitung stellte aus Sicht des Staates einen Segen dar, wenn es sich um erwünschte Informationen handelte, war sonst aber ein Fluch. Die Kommerzialisierung der neuen Ware Buch wurde daher schon rasch vom Bemühen um eine staatliche Kontrolle begleitet und mündete in den systematischen Aufbau eines Zensurwesens unter Philipp II. ${ }^{18}$

Man muss sich diese sattsam bekannten historischen Hintergründe vergegenwärtigen, wenn man die Besonderheiten des Autorschaftskonfliktes zwischen Mateo Alemán und seinem Rivalen, dem dann der zwischen Cervantes und Avellaneda folgte, sachlich angemessen erfassen will. Dass der kommerzielle Erfolg eines Textes Konkurrenten auf den Plan rief, die sich durch allographe Fortsetzung der Geschichte mit am symbolischen und ökonomischen Wert des Textes beteiligen wollten, ist ja an sich nicht bemerkenswert, sondern liegt in der neuen, technisch produzierten $>$ Natur des Buches. In Spanien zeigte sich der Kommerzialisierungseffekt paradigmatisch bereits an den beiden großen Publikumserfolgen des frühen 16. Jahrhunderts, der Amadís-Reihe und dem Celestina-Zyklus. In beiden Fällen wirkte Feliciano de Silva mit seinen Fortsetzungen des Ausgangstextes maßgeblich für eine Zyklenbildung, wobei er im Falle der Amadís-Fortsetzungen Montalvos die genealogische Anlage des Stoffes dazu nutzen konnte, seine Werkfortsetzung durch Einführung eines Neffen von Amadis, Lisuarte de Grecia (1514), quasi biologisch zu begründen, während er im Falle der Celestina auf magische Kosmetik setzt und die Protagonistin eine fingierte Auferstehung inszenieren lässt, die ihr >neues` Leben und damit die Verlängerung des Werkes von Fernando de Rojas ermöglicht. ${ }^{19}$

An diese Tradition romanhafter Serienbildung aus dem frühen 16. Jahrhundert zu erinnern ist nicht nur deshalb angebracht, weil ohne sie die Gestalt des verrückten Lesers Don Quijote nicht möglich geworden wäre - das erste Kapitel schildert ja, wie der Junker beim Versuch, den »verwickelten Erörterungen « Feliciano de Silvas zu folgen, den eigenen Verstand verliert und an die Realität der Fiktion zu glauben beginnt (I, 1, S. 40/38) -, sondern auch, weil

anderen kleinen«. Ich zitiere hier und im Folgenden unter Angabe von Buch, Kapitel und doppelter Seitenzahl, wobei sich die erste auf den spanischen Originaltext bezieht, die zweite auf die deutsche Übersetzung von Anton M. Rothbauer (Don Quijote de la Mancha, hg. u. übers. v. Anton M. Rothbauer, Frankfurt a. M: Zweitausendeins 1997).

$18 \mathrm{Zu}$ Aufbau und Entwicklung des staatlichen Kontrollwesens, das in Spanien zwar eng mit dem kirchlichen zusammenarbeitete, aber rechtlich stets unabhängig blieb, vgl. die Übersicht bei María Marsá, La imprenta en los Siglos de Oro, Madrid: Laberinto 2001, S. 23-35.

19 Vgl. Feliciano de Silva, Segunda Celestina, hg. v. Consolación Baranda, Madrid: Cátedra 1988, S. 191. 
vor dem Hintergrund der zyklischen Fortsetzungspraxis in der Frühphase des Buchdrucks die eigentliche Neuheit des Autorstreits zwischen Alemán, Cervantes und ihren pseudonymen Konkurrenten erkennbar wird. Zwischen den Literaturzyklen des beginnenden und den großen Romanwerken des späten 16. Jahrhunderts liegt der Aufbau des staatlichen Zensurwesens, das zu einer Stärkung von Autorschaft führte. Für die Zensur wurde die eindeutige Zurechenbarkeit von Büchern zu einem Autoren grundlegend. Mit der Errichtung des ersten staatlichen Index durch Valdés 1559 und später durch die so genannte »ley del silencio« wurde das Publizieren ohne Angabe der Autorschaft zu einem Strafbestand, der automatisch zur Aufnahme in die Liste der librorum prohibitorum führte ${ }^{20}$ und die zuvor relativ verbreitete Praxis anonymen Publizierens beendete. Die Nennung des Autornamens wurde ab diesem Zeitpunkt zu einem obligatorischen Bestandteil des Paratextes und stellte keine Option mehr dar in einem theoretisch offenen Spektrum zwischen Onymat, Anonymat und Pseudonymat. ${ }^{21}$ Das enorme Anschwellen des paratextuellen Bereiches und die steigende Relevanz des Autornamens sind Folgen einer Verrechtlichung der Literatur und eines erhöhten Legitimationsdrucks, der zu einer ganzen Serie von Autorisierungsverfahren führte. ${ }^{22}$

Zwischen der erhöhten Verantwortlichkeit des Autors und seiner weiterhin vorhandenen Abhängigkeit innerhalb des literarischen Patronagesystems geriet die Funktion des Autornamens in eine instabile Lage, wie sie für die Schwellensituation der Frühen Neuzeit zwischen Mittelalter und Moderne typisch ist. Sie ganz mit der modernen, auf der Idee von Werkeinheit und der (erst im 19. Jahrhundert rechtlich verbindlich verankerten) Vorstellung von >geistigem Eigentum gestützten Konzeption von Autorschaft kurzschließen zu wollen ${ }^{23}$, hieße gerade das historisch Spezifische der Neuzeit zu übersehen. ${ }^{24}$ Die Forschung zu Alemán und Cervantes ist aber durchzogen von einer

20 Fernando de Valdés schlug bereits 1558 in einem Dokument, das sich heute im Archiv von Simancas befindet, ausdrücklich das Verbot anonymer Publikationen vor - vgl. dazu den Beleg bei Jesús Martínez de Bujanda, Index de l'Inquisition espagnole 1551, 1554, 1559, 1984, Sherbrooke: U de Sherbrooke 1984, S. 95.

21 Vgl. dazu Gérard Genette, Seuils, Paris: Seuil 1987, S. 41-58.

$22 \mathrm{Zu}$ den einzelnen Bestandteilen des Paratextes im Buch des Siglo de Oro vgl. Marsá, La imprenta, S. 37-60.

23 Rechtlich kannte man in der Antike und im Mittelalter nur das Eigentumsrecht am Manuskript. Die geistige Leistung galt als res extensa commercium. Das corpus iuris leitet sich vor der Etablierung eines Autorenrechtes allein von der Materialität des Manuskripts und des Codex ab.

24 Bei aller berechtigten Kritik an seinen Ausführungen, die historisch zu wenig nuanciert sind, bleibt es das Verdienst von Michel Foucault, nachdrücklich auf die geschichtliche Variabilität der diskursiven Funktion des Autors hingewiesen zu haben : »Qu'est-ce qu'un auteur? «, in: Ders., Dits et écrits 1954-1988, hg. v. Daniel Defert/François Ewald, Paris: Gallimard 1994, Bd. 1, S. 817-849. Den komplexen Prozess des Wandels des Autorschaftskonzeptes, der gewiss nicht erst mit dem Autorenrecht der Moderne beginnt, wie Foucault selbst nahe legt, sondern schon in der Frühen Neuzeit eingeleitet wurde, analysieren Roger Chartier, Culture écrite et société. L'ordre des livres (XIVe - XVIIIe siècle), Paris: Albin Michel 1996, S. 4580, sowie Gerhard Lauer, »Offene und geschlossene Autorschaft. Medien, Recht und der To- 
solchen anachronistischen Neigung zur Modernisierung der Autoren, die sie gegen den vermeintlich unlauteren Ideendiebstahl der Fortsetzungen in Schutz nehmen zu müssen glaubt - bis hin zur direkten Kriminalisierung der >Apokryphen.$^{25}$ Der Affekt gegen die Rivalen ist dabei umso unsinniger, als er der intentio auctoris nur auf halben Wege folgt: Übernommen wird zwar die moralische Abwertung des anderen Autors, nicht aber die gleichzeitig geleistete Anerkennung der produktiven strukturellen Funktion der Instanz des Mediators. Denn die Tatsache, dass sowohl Alemán als auch Cervantes die allographen Fortsetzungen ausdrücklich mit in die Fortsetzung der eigenen Geschichte aufnehmen und zur Komplexitätssteigerung ihrer Texte nutzten, lässt sich nicht als bloßer Ausschluss deuten, sondern stellt eine Überbietung auf dem Wege der Inklusion des Anderen dar. Die Literarisierung des Autorschaftskonfliktes bei Alemán und Cervantes ist damit nicht Symptom moderner Individualität, sondern Kennzeichen eines frühneuzeitlichen Willens zur Autorschaft, dessen Subjekte sich ihrer realen Abhängigkeiten dabei (noch) sehr bewusst waren. ${ }^{26}$

\section{Alemán und der andere Autor im Guzmán de Alfarache}

Mateo Alemán war für Cervantes ein Vorbild und Mediator im Sinne Girards nicht nur wegen des enormen Publikumserfolges, den er mit der Publikation des ersten Teiles des Guzmán 1599 erreicht hatte, sondern auch als ein hoch professioneller Autor, der ganz im typographischen Zeitalter angekommen war und sich dessen Bedingungen hervorragend angepasst hatte. José María Micó hat gezeigt, wie stark Alemán um eine permanente Kontrolle des Drucks und der Verbreitung seiner Werke bemüht war und wie sehr er versuchte, dem durch den komplexen Vermittlungsweg im Druckprozess drohenden Kontrollverlust über die Endgestalt seines Textes entgegenzutreten, angefangen vom Einsatz eigener Druckstöcke über die vertragliche Verpflichtung des Druckers, auf seinem privaten Anwesen zu drucken, um so den täglichen Output direkt

pos von der Genese des Autors im 18. Jahrhundert«, in: Detering (Hg.), Autorschaft, S. 461478.

25 Vgl. als eines von vielen Beispielen die Bemerkungen des Herausgeber Luis Gómez Canseco in seiner Ausgabe von Fernández de Avellaneda, El ingenioso hidalgo Don Quijote de la Mancha, Madrid: Biblioteca Nueva 2000, S. 10.

26 Meine Kritik an einer romantischen Lektüre des Quijote zielt also, dies soll an dieser Stelle explizit gesagt sein, nicht darauf ab, gegen eine vermeintlich >falsche< Modernisierung eine vorgeblich authentischere, weil dem historischen Verstehenshorizont des 17. Jahrhundert entsprechende Lektüre des Romans zu proklamieren, wie es dies die in der amerikanischen Hispanistik als »hard school« bekannte Forschungsrichtung unternimmt, im Gegenteil soll eine moderne Lektüre gestärkt werden, indem gezeigt wird, dass die Modernität des Romans auch ohne die illusionäre genieästhetische Voraussetzung einer selbstgenetischen Autonomie des >Schöpfers« gewonnen werden kann, auf dem Weg einer Anerkennung der produktiven Funktion des Anderen. 
vor Ort kontrollieren zu können, bis hin zum (wahrscheinlichen) Eigendruck im Falle der von ihm übertragenen Horaz-Oden. ${ }^{27}$ Wo das autographe Manuskript im Prozess der typographischen Vervielfältigung zur bloßen copia zu werden droht $^{28}$, und die >originale< Schrift auf dem Wege der unterschiedlichen Stationen des Drucks korrumpierbar war, musste ein Autor schon sehr kenntnisreich in die Prozesse des Druckens eingreifen, um halbwegs sicherstellen zu können, dass er sein persönliches Idiom im fertigen Produkt wiedererkennen konnte. Die typographische Reproduktionstechnik stellte noch für die Autoren des frühen 17. Jahrhunderts eine durchaus unheimliche Macht dar. Einerseits sicherte der Buchdruck eine beschleunigte Verbreitung der Schrift und damit ein Überleben der Autoren im kollektiven Gedächtnis der Gemeinschaft, wie die Apologeten immer wieder betonten. Andererseits war die Beziehung zwischen dem >Vater der Gedanken und dem von ihm informierten Endprodukt nicht mehr von der körperlichen Präsenz geprägt, welche die Zeugungsmetaphorik im skriptographischen Zeitalter noch plausibel machte. ${ }^{29}$ Gedruckte Bücher stellen eben nicht mehr notwendig weiterhin »wahrhafte Bildnisse und ewige Repräsentanten des Geistes ihrer Herren« dar, wie etwas Cristóbal Suárez de Figueroa zum Lob des Druckwesens im Rahmen seiner Plaza Universal de todas ciencias y Artes (1615) unter Bezug auf den Heiligen Hieronymus noch voraussetzt ${ }^{30}$, sondern konnten hässliche Fehlgeburten darstellen, in denen der Autor seine Intentionen nur wie in einem Zerrspiegel reproduziert fand. Das merkwürdige Verhalten des Erzählers im ersten Teil des Quijote, der als Stiefvater (»padrastro«) keine auktoriale Verantwortung für das ihm als Geschichte vorliegende »häßliche und aller Anmut bare Kind « übernehmen will (I, Vorrede, S. 23/9f.), zeigt noch etwas vom Entsetzen, das Autoren in der Frühphase des Drucks beim Blick in >ihre< Bücher überkommen konnte, wie im Falle des Kolmarer Artztes Laurenz Freis, der 1518 einen Spiegel der Artzny herausgebrachte hatte und rückblickend das fertige Produkt als Monstrum beschreibt:

Wann da ichs erstmals dem trucker befohlen/ ist es so jaemmerlichen an tag kummen/ das ich/ da ich's erstmals anblickt/ meynt ich hett ein moerwunder geporen/ wann so vil darinn verkeret vnnd durch ein ungelerter setzer also zerbo-

27 Vgl. José María Mico, »Mateo Alemán y el Guzmán de Alfarache: La novela, a pie de imprenta«, in: Francisco Rico (Hg.), Imprenta y crítica textual en el siglo de oro, Valladolid: Centro para la Edición de los Clásicos Españoles 2000, S. 151-169.

28 Als solches wurde es in der Fachsprache der Drucker bezeichnet, wie etwa Juan Caramuel y Lobkowitz' Syntagma de arte typographica belegt, Art. X: »In typographeio, manuscriptus ipsum vocatur >copia<, libri impressi >exemplaria«. Ich zitiere nach der Textausgabe, die als Appendix bei Rico, Imprenta y critica textual, beigefügt ist, hier S. 282.

29 Zum Topos des Buchs als Kind vgl. Ernst Robert Curtius, Europäische Literatur und lateinisches Mittelalter, Tübingen: Francke ${ }^{11} 1993$, S. $143 \mathrm{ff}$.

30 Vgl. die Belegstelle bei Francisco Rico, Imprenta y crítica textual, Appendix I, hier S. 261. 
chen was/ noch darmit nit genuog/ sunder auch vil nerrischer bossen hinzuo gethon/ deren ich nye keinen in meinen $\sin (\mathrm{n})$ nam zuomachen. ${ }^{31}$

Anders als Cervantes pflegte Alemán kein nostalgisches Verhältnis zur oralen und skriptographischen Kultur mehr und begegnete den möglichen Tücken der Technik durch den Versuch einer möglichst umfassenden Kontrolle. Ähnlich offensiv ist auch seine Haltung gegenüber dem Konkurrenten, der ihm mit der angekündigten Fortsetzung der primera parte zuvorgekommen war. Er publiziert die eigene Fortsetzung nicht einfach in der Hoffnung, sich mit ihr auf dem Markt durchsetzen zu können, sondern schreibt ihr den Konflikt mit dem fremden Autor direkt ein und macht ihn damit öffentlich. Die Einschreibung des Konkurrenten in das eigene Werk geschieht dabei in doppelter Form, sowohl im paratextuellen Vorraum, wo der Autorschaftskonflikt direkt als solcher ausgestellt wird, als auch im Inneren der erzählten Geschichte durch die Einführung der Figur Sayavedras, mit deren Hilfe die Konkurrenzsituation zwischen den Autoren auf die Ebene eines Handlungskonfliktes transponiert wird.

Im Vorraum zur Fiktion geht es Alemán zunächst um Autorisierung, Legitimierung und Propagierung des eigenen Erzählens. Die Existenz einer rivalisierenden Fortsetzung nutzt er dabei in geschickter Weise zur Aufwertung der eigenen Erzählung. Aus der dedicatoria an Don Juan de Mendoza erfährt der Leser, dass das Ausgangsprojekt des Werkes durch den »desafío que me hizo sin ella el que sacó la segunda parte de mi Guzmán de Alfarache« entscheidend verändert werden musste:

Que, si decirse puede, fue abortar un embrión para en aquel propósito, dejándome obligado, no sólo a perder los trabajos padecidos en lo que tenía compuesto, mas a tomar otros mayores y de nuevo para satisfacer a mi promesa. ${ }^{32}$

Wie weit Alemáns Arbeiten an dem zweiten Teil seines Romans tatsächlich schon gediehen waren, lässt sich heute nicht mehr rekonstruieren und es ist müßig, über den Status des unfreiwillig aufgegebenen »Embryonen« zu spekulieren. Entscheidender scheint mir die taktische Funktion der Rede an dieser

31 Zitiert nach Michael Giesecke, Der Buchdruck in der frühen Neuzeit. Eine historische Fallstudie über die Durchsetzung neuer Informations- und Kommunikationstechnologien, Frankfurt a. M.: Suhrkamp 1991, S. 454.

32 Mateo Alemán, Guzmán de Alfarache, hg. v. Benito Brancaforte, Madrid: Cátedra ${ }^{3} 1984$, Bd. II, S. 16: »Längst ist bekannt, daß ich durchaus im Rechte bin, wenn ich in meiner Sache auf die Herausforderung erwidere, die der Räuber des Zweiten Teiles meines Guzmán von Alfarache zu Unrecht an mich richtete. Wenn man nämlich so sagen darf, kam sein diesbezügliches Verhalten der Abtreibung eines Embryonen gleich und zwang mich nicht allein, der bis dahin beim Verfassen erlittenen Mühsal verlustig zu gehen, sondern auch, noch größere auf mich zu nehmen und mein Versprechen zum zweiten Male zu erfüllen«; Das Leben des Guzmán von Alfarache, aus d. Span. v. Rainer Specht, in: Horst Baader (Hg.), Spanische Schelmenromane, Bd. 1, München: Hanser 1964, hier S. 405. In folgenden Zitaten werden nach Angabe von Teil, Buch und Kapitel jeweils die Seitenangaben des spanischen Originals und dann der deutschen Übersetzung genannt. 
Stelle der segunda parte: sie begründet den Neuigkeitswert der eigenen Fortsetzung und steigert dramatisch die Lust auf deren Lektüre. Angekündigt wird ein Kampf mit einem Gegner, dessen Größe herausgestellt wird (»un autor tan docto«), um den letztendlichen Sieg des Helden ungewiss und damit umso spektakulärer erscheinen zu lassen. ${ }^{33}$

Mit der Vorrede an den Lector wird die Rolle des Anderen, der bisher als gefährlicher, aber edler Feind fungierte, dann verschoben, nämlich sozial erniedrigt. Er wird nun als unehrenhafter Dieb dargestellt. Gleichzeitig ist damit aber auch der Autor der >authentischen< segunda parte, der sich in der Widmungsrede als unerschrockenen edlen Ritter stilisiert hatte, auf eine andere Ebene abgesunken und hat sich dem pikarischen Protagonisten der eigenen Erzählung angenähert. Entscheidend ist, dass der Autor in dieser Rolle nicht dazu geeignet ist, den vermeintlichen Diebstahl des anderen moralisch zu denunzieren. ${ }^{34}$ Dessen imitatorische Praxis wird entsprechend auch ausdrücklich als legitimes Mittel im schriftstellerischen Konkurrenzkampf bestätigt, ein Kampf, der mit der nun vorliegenden sauthentischen` Fortsetzung nicht etwa beendet, sondern in die Zukunft projiziert und damit virtuell unabschließbar wird. ${ }^{35}$ Statt sich sozial und moralisch vom Anderen zu distanzieren, geht Alemán in seiner Rolle als Autor ein agonales mimetisches Verhältnis zu ihm ein und weitet damit zugleich die Kampfzone seines pikarischen Protagonisten aus. Der Guzmán der segunda parte hat nicht mehr nur sein eigenes Leben zu bessern, sondern muss sich im direkten Vergleich zu seinem >falschen< Imitat zugleich als der bessere Pícaro profilieren, weil er als Stellvertreterfigur gegen Sayavedra für seinen Autor einzustehen hat. Eine doppelte Mission, welche das ohnehin schon problematische Verhältnis von pikaresker Lebensgeschichte und dem aus ihr zu ziehenden moralischen Nutzwert, die Dialektik von conseja und consejo, auf die in der Ansprache an den discreto lector im

33 Die Aufwertung Mateo Lujáns zum poeta doctus ist dabei ironisch zu verstehen, denn die direkten Quellenübernahmen sind in seinem Roman relativ offensichtlich und von der Forschung inzwischen auch schon mehrfach nachgewiesen worden. Vgl. Donald Mc Grady, »Mateo Luján y López Pinciano«, in: Thesaurus. Boletín del Instituto Caro y Cuervo 21 (1966), S. 331-340, sowie Bernadette Labourdique/Michel Cavillac: »Quelques sources du Guzmán apocryphe de Mateo Lujan«, in: Bulletin hispanique 71 (1969), S. 191-217. Dass die Gelehrtheit Mateo Lujáns eine aus zweiter Hand darstellte, war sicher auch Mateo Alemán bekannt.

34 Dass die Rede vom Diebstahl keinen tatsächlich als kriminellen Akt zu wertenden Manuskriptraub meint, sondern metaphorisch den (zu jener Zeit noch nicht justiziablen) Raub von Ideen, ist in der ganzen Argumentationslogik des Vorwortes impliziert, denn wenn der Text Luján de Sayavedras wirklich einem fertigen Manuskript Alemáns entsprechen würde, wäre es unsinnig, ihm Abweichungen von der ursprünglichen Autorintention vorzuwerfen.

»Sólo nos diferenciamos en haber él hecho segunda de mi primera y yo en imitar su segundo. Y lo haré a la tercera, si quisiere de mano hacer el envita, que se lo habré de querer por fuerza, confiado que allá me darán lugar entre los muchos « (II, S. 20/410: »Nur unterscheiden wir uns dadurch, daß er aus meinem Ersten einen Zweiten machte und ich seinen Zweiten nachahme. Ich werde es beim Dritten ebenso machen, wenn er mir zuvorkommt und das Spiel eröffnet; auch wird mir nichts anderes übrig bleiben, als es zu wollen, im Vertrauen darauf, dass man mir drüben ein Plätzchen bei den Toten gibt«.) 
ersten Teil insistiert worden war $^{36}$, zusätzlich erschwert, da der hermeneutische Konflikt, den der Erzähler in dialogischer Form mit seinem Leser und gegen ihn um den Sinn seines Lebens austrägt ${ }^{37}$, nun über den Umweg der Schrift eines anderen ausgetragen werden muss. Der andere Autor ist ja zunächst auch ein Leser des ersten Teils gewesen und ist als solcher gescheitert, wie es im Blick auf alle zukünftigen Nachahmer mahnend heißt: »Advierte en esto que no faciliten las manos a tomar la pluma sin que se cansen los ojos y hagan capaz a el entendimiento; no escriban sin que lean, si quieren ir llegados a el asunto, sin desencuadernar el propósito «. ${ }^{38}$ Luján de Sayavedra habe die intentio auctoris des Originals nicht richtig erfasst und entscheidende Sinnelemente überlesen. Statt aus dieser Tatsache die Konsequenz zu ziehen, in seiner Vorrede die eigene Intentionalität diesmal eindeutig zu profilieren und damit die Möglichkeit zur Wiederholung einer ähnlichen Fehllektüre auszuschließen, wird das Anliegen des eigenen Erzählens in uneindeutig-spannungsvoller Weise ausgestellt, denn der Vorwurf an den anderen Autor geht in durchaus konträre Richtungen und treibt dabei gerade die Frage nach der Vermittelbarkeit beider Argumente als entscheidendes Interpretationsproblem hervor.

Zunächst wird nämlich die Ebene des consejo als >eigentlicheく Sinnschicht des Werkes hervorgehoben und der didaktische Nutzwert des Erzählten, seine Funktion als aus der Übersichtsperspektive des Wachturms (atalaya) gewonnene Lehre betont. Diese Funktion habe der Rivale in seiner Fortsetzung nicht angemessen berücksichtigt, da er seinen Guzmán zwar Studien in Alcalá de Henares aufnehmen lässt, dessen Gelehrsamkeit jedoch unglaubwürdig macht, wenn er ihn als »distraído y mal sumulista« (»liederlichen und schlechten Summulisten«, II, S. 21/410) darstellt und ihn das Studium vorzeitig abbrechen lässt. Unterstützt wird dieses Insistieren auf dem moralisch-didaktischen Nutzwert des Textes auch durch den veränderten Titel der segunda parte, in der Alemán nun die zentrale Bedeutung seines Erzählers als atalaya hervorhebt und damit deutlich gegen die Fortsetzung Mateo Lujáns abgrenzt ${ }^{39}$, sowie

$36 »$ Haz como leas lo que leyeres y no te rías de la conseja y se te pase el consejo« (I, S. 86/73: »Sieh zu, daß du liest, was du liest, und nicht über die Fabel lachst und dadurch ihre Moral verpaßt $\ll$.)

37 Den Charakter des Textes als dialogisches Streitgespräch hat u.a. schon Helen H. Reed herausgearbeitet: »Thus the process of the work is dialogical, an unending argument in which a proper synthesis of various contradictory elements is never achieved. The text is rather like a conversation between two protagonists who cannot resolve their quarrel« (The Reader in the Picaresque Novel, London: Tamesis 1984, S. 75).

38 II, S. 20/410: »Ich bemerke bei dieser Gelegenheit, daß sie nicht zur Feder greifen sollten, bevor sie ihre Augen angestrengt und ihren Verstand gewitzigt haben; sie sollten nicht schreiben, bevor sie lesen, sofern sie ihrem Gegenstand gerecht werden und nicht den Plan durcheinanderbringen wollen «.

39 Segunda parte de la vida de Guzmán de Alfarache. Atalaya de la vida humana por Mateo Alemán su verdadero autor. Der Titel des ersten Teils hatte in der editio princeps Primera parte de Guzmán de Alfarache gelautet, alle weiteren Ausgaben tragen als Titel Primera parte de la vida del pícaro Guzmán de Alfarache, eine Titelgebung, an die dann auch Mateo 
durch das Eligo des Alférez Luis de Valdés, der ebenfalls die didaktische Absicht des Werkes betont.

So weit, so gut. Im zweiten Argumentationsschritt begibt sich der Autor in seinem Vorwort an den Leser aber wieder ganz auf die Ebene der consejas, die er als uneigentliche Schicht des Werkes zuvor abgewertet hat, und wirft auf dieser Ebene dem pseudonymen Autor vor, nicht weit genug gegangen zu sein und das kriminelle Potential des Protagonisten unausgeschöpft gelassen zu haben. Weder sei die angekündigte Rache gegen die eigenen Verwandten ausgeführt worden, noch verdiene der Pícaro Mateo Lujáns für seine Taten den Ehrennamen eines »ladrón famosísimo« (»sehr berühmten Diebes«, II, S. 21/410). Beide Ankündigungen werden nun in der eigenen Erzählung verwirklicht und dabei die Figur des Anderen in Dienst genommen. Sayavedra hilft Alemáns Protagonisten im zweiten Teil als Diener bei der Durchführung seiner Rache gegen die Verwandten, muss dabei dessen Überlegenheit als Dieb anerkennen und stirbt schließlich auf dem Weg von Italien nach Spanien im Meer, nachdem er sich in geistiger Umnachtung selbst von Bord gestürzt hat (Vgl. II, II.7-9). Zuvor hat er jedoch »mitten im Sturm und in der größten Bedrängnis, während die anderen schreiend ihre Sünden bekannten«, seinen eigenen Status als Doppelgänger und »Schatten« Guzmáns bekannt (II, II.9, S. 274/651). Die Einführung des Rivalen in die eigene Fiktion dient somit nicht nur dazu, die pikarische Identität des eigenen Guzmáns zu schärfen, zu der moralische Skrupellosigkeit und perfekte Simulationsfähigkeit gehören, sondern spiegelt auch in invertierter Form den Charakter von dessen Erzählung als »Generalbeichte $\aleph^{40}$ und weist auf die spektakuläre Wende seiner Lebensgeschichte voraus, die mehrfach gestufte Konversion, die der Forschung

Luján anschließt. Dass Alemán die Atalaya-Funktion seines Erzählens erst in Reaktion auf die >apokryphe< Fortsetzung betonte, wie schon Sobejano, »De la intención y valor del Guzmán«, in: Romanische Forschungen 71 (1959), S. 267-311, feststellte, dürfte kaum bestreitbar sein. Die von Michel Cavillac gegen Sobejano ins Feld geführte Tatsache, dass bereits im privilegio real der Erstausagabe durch Don Luis de Salazar der Untertitel atalaya de la vida humana erwähnt ist (vgl. Picaros y mercaderes en el Guzmán de Alfarache. Reformismo burgués y mentalidad aristocrática en la España del Siglo de Oro, a. d. Frz. v. Juan M. Azpitarte, Almagro/Granada: U de Granada 1994, S. 98), stellt keinen wirklichen Einwand gegen die These von einer intertextuellen Dependenz des zweiten Teils des Guzmán dar. Die bewussten Eingriffe, die Mateo Alemán zwischen der Erstausgabe und den weiteren Editionen des ersten Teils vornahm und die auch Veränderungen des Titelblatts einschließen (z. B. die Tilgung des Zusatzes »criado del Rey don Felipe III«), zeigen vielmehr, dass er zu diesem Zeitpunkt, vor der Rivalität mit Mateo Luján, der atalaya-Semantik kein besonderes Gewicht beimaß. Die zunächst fallen gelassene Titelvariante erhielt durch den Autorschaftsstreit neue Bedeutung und konnte erfolgreich reaktiviert werden.

$40 \gg$ Digo - si quieres oírlo - que aquesta confesión general que hago, este alarde público que de mis cosas te represento, no es para que me imites a mí; antes para que, sabidas, corrijas las tuyas en ti« (II, I.1, S. 38/423: »Ich erkläre - sofern du es hören willst - daß diese meine Generalbeichte und dieser dir gebotene öffentliche Überblick über meine Angelegenheiten nicht dazu dienen soll, daß du mir nachahmst, sondern daß du sie kennen lernst und dadurch die deinigen besserst $\ll$.) 
bis heute nicht nachlassendes Kopfzerbrechen bereitet. ${ }^{41}$ Mit und gegen den anderen Autoren hatte Alemán den Kontrast zwischen consejas und consejos noch weiter zugespitzt und die Frage nach deren Vermittlung umso drängender gemacht. Für Francisco Rico und viele andere Interpreten stellt die Konversion des >bösen< Guzmanillos (bzw. Guzmán actor) zu Guzmán dem Guten (Guzmán auctor) die Lösung dieser Frage dar, das entscheidende erzähltechnische Ereignis, von dem aus die Episoden der Lebensgeschichte als Elemente eines einheitlichen Konstruktionsprinzips verstehbar würden. ${ }^{42}$ Rückblickend interpretiert, von der Konversion des Pícaro zum reuigen Sünder aus, werde die Erzählung der Lebensgeschichte als ein didaktisch-moralisches Negativexempel motiviert und die Steigerung der pikaresken consejas im zweiten Teil würde somit der Steigerung ihrer Funktion als eines Kontrastmittels dienen, um die Wende der Bekehrung umso eindrucksvoller gestalten zu können. Nichts zwingt jedoch, die Konversion auch als definitiven Abschluss der Fiktion zu verstehen und der behaupteten moralischen Besserung des Erzählers ohne weiteres zu glauben, zumal die Konversion interessanterweise in keinem der Paratexte angekündigt und als das entscheidende sinntragende Element vorbereitet wird. Wenn die Konversion die atalaya-Position des Erzählers überhaupt erst sichert, war dem Autor entweder das entscheidende Element seiner Erzählstruktur nicht bewusst oder er hat absichtlich verschwiegen. Ausdrücklich legitimiert (und zwar mehrfach!) hat er dagegen die Fortsetzbarkeit der erzählten Lebensgeschichte und damit auch die Möglichkeit zum Auftritt neuer literarischer Rivalen geschaffen. ${ }^{43}$ Sie werden nicht nur im Vorwort an den Leser antizipiert, sondern erhalten mit dem letzten Absatz seines Textes sogar freie Hand zur Fortsetzung des mimetischen Autorschaftsstreits. ${ }^{44}$ Anders als im Falle der Beichte von Guzmáns schattenhaftem alter ego, in der sich die Wahrheit der Fiktion des anderen Autors offenbart - ihre Abhängigkeit vom Original, dem sie ihre Existenz verdankt - fallen in Guzmáns Lebensbericht Penitenz und Lebensende nicht zusammen. Das Entscheidende seines Lebenswegs bleibt unklar und wird als fehlender Rest und Übertrag

41 Michel Cavillac unterscheidet drei aufeinanderfolgende Konversionen Guzmáns, die moralische, die politische und schließlich die poetische, mit der er vom Handelnden zum Erzähler wird: »Les trois conversions de Guzmán de Alfarache«, in: Bulletin Hispanique 95 (1993), S. $149-201$.

42 Vgl. Francisco Rico, La novela picaresca y el punto de vista, Barcelona: Seix Barral ${ }^{4} 1989$, S. $69 f$.

43 Vgl. Angel San Miguel, »Tercera Parte de Guzman de Alfarache. La promesa de Alemán y su cumplimiento por el portugués Machado de Silva«, in: Iberoromania, N.F. 1 (1974), S. 95120 , hier S. $100 \mathrm{ff}$.

44 „Aquí di punto y fin a estas desgracias. Rematé la cuenta con mi mala vida. La que después gasté, todo el restante della verás en la tercera y última parte, si el cielo me la diere antes de la eterna que todos esperamos.« (II, III.9, S. 480/845: »Hier habe ich einen Punkt und Schlußstrich unter diese Kette von Mißgeschicken gesetzt. Ich habe die Rechnung mit meinem schlimmen Leben quitt gemacht. Das, was ich in der Folgezeit während seines ganzen Restes verbrachte, kannst du im dritten und letzten Bande sehen, sofern es mir der Himmel noch vor dem ewigen gibt, auf das wir alle hoffen«.) 
(»restante«) in die Zukunft verschoben, die Frage nämlich, welche sozialen und lebenspraktischen Konsequenzen seine Bekehrung haben wird und ob sie ihn in die Freiheit führt. Mateo Luján hatte am Ende seines zweiten Teils die Galeere als wahre Hölle geschildert, als eine endlose Gewaltspirale, in der auch die Wahrheit zugrunde geht, weil jeder gegen jeden kämpft und den anderen diskreditiert ${ }^{45}$, jedoch für einen dritten Teil Guzmáns Freiheit in Aussicht gestellt und damit den unfreien Status der Erzählers ignoriert, den Alemáns Formulierung in der Erklärung zum Verständnis dieses Buches eigentlich logisch implizierte. ${ }^{46}$ Alemán falsifiziert dieses Freiheitsversprechen seines Rivalen nicht direkt, sondern suspendiert es bis auf weiteres, indem er die Ankündigung eines dritten Teils übernimmt, aber bewusst offen lässt, ob es zur Freilassung kommen wird. Er gewährt seinem Protagonisten lediglich eine prekäre, vorläufige und relative Freiheit und lässt ihn dann - und damit uns Leser - mit der Erwartung auf eine Begnadigung durch die königliche Majestät allein. Was dem Glaubensbekenntnis folgt - ein neues Leben in Freiheit, wie es Machado da Silva in seiner Fortsetzung ausmalte ${ }^{47}$, oder vielleicht umgekehrt die Enttäuschung der Freiheitshoffnung, was Michel Cavillacs Argumentation zufolge symptomatisch für das historische Scheitern eines bürgerlich-merkantilistischen Reformprojektes wäre, wie es Alemán zusammen mit seinem Freund Pérez de Herrera vertrat ${ }^{48}$ - diese Grundsatzfrage bleibt in letzter Konsequenz unentscheidbar, weil Alemán die textuelle Grundlage für eine objektivierbare Entscheidung über das eigene Werkfinale hinaus in die Zukunft verschiebt.

Der Autor hat den Konflikt mimetischen Begehrens nach der idealen Form des Romans so also keineswegs beendet, sondern weiter vertieft, indem er durch Integration der Autorschaftsrivalität in die eigene Fiktion und durch eine zweifelhaft bleibende moralische Erhebung des Pícaro zum Atalaya den Einsatz, der mit seinem Guzmán auf dem Spiel stand, der didaktisch-ideologische und der ästhetisch-literarische Wert einer auf Realismus ausgerichteten Erzählprosa, bewusst noch einmal erhöhte: »Que, como el campo es ancho,

45 Vgl. Mateo Luján de Sayavedra, »Segunda Parte de la vida del pícaro Guzmán de Alfarache«, in : Angel Valbuena Prat (Hg.), La novela picaresca españõla, Madrid: Aguilar ${ }^{7} 1974$, Bd. 1, S. 721-876, hier S. 874.

46 Zum Zeitpunkt seiner Niederschrift müsste Guzmán (noch oder schon wieder?) Galeerenhäftling sein, wenn man die gewählte Zeitform des Präsens ernst nimmt: »Él mismo [d. h. Guzmán de Alfarache] escribe su vida desde las galeras, donde queda forzado al remo, por delitos que cometió, habiendo sido ladrón famosísimo como largamente lo verás en la segunda parte« (I, S. 89/74: »Er selber beschreibt sein Leben, während er auf der Galeere wegen begangener Delikte das Ruder schwingen muß, er war nämlich vorher ein berühmter Dieb gewesen, wie du im zweiten Teil ausführlich sehen wirst«.)

47 Mit einer Tercera Parte de Guzmán de Alfarache, in der Guzmán auch eine neue Herkunft erhält und seinem moralischen Bewusstseinswandel ein entsprechendes Handeln folgen lassen kann, bewies der portugiesische Autor de facto die Fortsetzbarkeit des Romans. Vgl. die Ausgabe des Textes durch Gerhard Moldenhauer, in: Revue Hispanique 69 (1927), S. 1-340, sowie die Ausführungen von Angel San Miguel, »Tercera Parte de Guzman de Alfarache«. 
con la golosina del sujeto, a quien también ayudaría la codicia, saldrán mañana más partes que conejos de soto «. ${ }^{49}$

\section{Cervantes und die anderen Autoren im Don Quijote}

»Print encourages a sense of closure, a sense that what is found in a text has been finalized, has reached a state of completion $\aleph^{50}$, so die ebenso lapidare wie kategorische Einschätzung Walter J. Ongs, nach dessen Ansicht die technischen Innovationen in der Gestaltung der Buchform strukturanaloge Folgen in der mentalen Organisation von Information zeitigten. Das Beispiel des Autors Aleman, bei dem das Vermögen und der Wille zu einer professionellen Kontrolle der finalen Gestalt des Textes gerade nicht mit einer »noetic closure«, einer auf Sinnkohärenz ausgerichteten Werkkonzeption einhergeht, spricht jedoch gegen einen allzu direkten Kurzschluss von Medien- und Mentalitätsgeschichte. Der Autor Cervantes ist ein weiteres Beispiel gegen eine Parallelisierung von Medientechnik und mentaler Formatierung, allerdings im gegenläufigen Sinne. Anders als Alemán, der im Bewusstsein der durch die beschleunigte Vervielfältigung gestiegenen Bedeutung der im Druck fixierten Lettern die definitive Textgestalt durch Überwachung des gesamten Druckprozesses zu kontrollieren und damit seine Autorschaft durchzusetzen versuchte, verfuhr Cervantes bei der Einrichtung seines Textes zum Druck eher nachlässig, wie die editio princeps des Don Qujote von 1605 zeigt. Neben einigen von den Druckern direkt zu verantwortenden Setzungsfehlern finden sich auch solche, die einer mangelnden Kontrolle des Autors über sein Endprodukt geschuldet sind, wie der berühmte Fall von Sanchos verschwundenem Esel beweist, auf den noch genauer einzugehen sein wird. Genau umgekehrt ist die Rollenverteilung aber im Hinblick auf die Schließung des informationellen Sinns: Wo Alemán den Sinn der Lebensgeschichte seines Helden offen hielt und damit sein >Originak weiteren Fortschreibungen aussetzte, fand Cervantes mit dem Tod seines Helden einen radikalen Schluss, wobei er bewusst mit dem eigenen unschlüssigen Schluss der primera parte seines Romans brach, an dem sich seinerseits Avellaneda bei seinem >apokryphen Quijote orientiert hatte. ${ }^{51}$ Der

49 II, S. 20/410: »der Gegenstand verlockt, und vielleicht hilft auch die Habgier ein wenig nach; deshalb kommen morgen gewiß mehr Teile heraus, als Kaninchen aus dem Walde.« - Die Entstehung einer ganzen Reihe weiterer novelas picarescas in Reaktion auf den Guzmán zeigt, dass diese Einschätzung vom verlockenden, Nachahmung stimulierenden Wert seines Romans nicht falsch war.

50 Walter J. Ong, Orality and Literacy. The Technologizing of the Word, London/New York: Methuen 1982, S. 132.

51 Für eine Analyse der Schlüsse des ersten und zweiten Teils des Quijote vgl. Hanno Ehrlicher, »Fin sin final. Sobre la inconclusión del Quijote de 1605«, in: Criticón 96 (2006), S. 47-67, sowie Martin von Koppenfels, »Terminar - Abjurar. El último capítulo del Don Quijote«, ebd., S. 69-85. 
Aufforderung zum Weitererzählen, mit welcher der erste Teil unter Bezugnahme auf die Tradition mündlicher Vortragskunst der Troubadours endete - »Forse altri canterà con miglior plettro« (I.52, S. 597/638) ${ }^{52}$ - steht nun das über seine Feder vermittelte Diktat des binnenfiktionalen Autors Cide Hamete gegenüber ${ }^{53}$, womit ein exklusiv-unmittelbares Verhältnis der Einheit zwischen Autor und Werk beschworen und die Figur eines störenden Dritten ausgeschlossen wird:

Para mí sola nació don Quijote, y yo para él, él supo obrar y yo escribir, solos los dos somos para en uno, a despecho y pesar del escritor fingido y tordesillesco que se atrevió o se ha de atrever a escribir con pluma de avestruz grosera y mal deliñada las hazañas de mi valeroso caballero, porque no es carga de sus hombros, ni asunto de su resfriado ingenio. ${ }^{54}$

Diese verabsolutierte, dem im Sinne Girards >romantischen< Begehren folgende Bindung zwischen Autor und Held, ist aber alles andere als der Beleg von Unmittelbarkeit, sondern verdankt sich einem langen Prozess der Selbstreflexion, in der die Auseinandersetzung mit der Instanz des Mediatoren ein ganz entscheidender Bestandteil ist. Durch den Mediator trianguliert ist das Verhältnis zum eigenen Werk für den Autoren Cervantes praktisch zunächst und vor allem in Gestalt des konkurrierenden Autors Avellaneda, dessen Fortsetzung des Don Quijote 1614 erschienen war. Die Auseinandersetzung mit dem >falschen Quijote, der dem Don Quijote von 1615 explizit ab Kapitel 59, implizit aber schon viel früher eingeschrieben ist ${ }^{55}$, stellt aber - und das unter-

52 Avellaneda greift diese Formel ebenso wie die Rede von den »archivos manchegos« in seiner eigenen Gestaltung des Schlusses auf, ersetzt dabei signifikanterweise aber das Plektrum des Troubadours schon mit der Feder, die Cervantes dann - gegen Avellaneda gewendet - wieder aufgreifen wird: vgl. Avellaneda, El ingenioso hidalgo, S. 721.

53

Wenn Cervantes' literarische Autorschaftsgestaltung, die José Manuel Martín Morán als ein Oszillieren zwischen Oralität und Druckschriftlichkeit beschrieben hat - „Cervantes: El juglar zurdo de la era Gutenberg «, in: Cervantes: Bulletin of the Cervantes Society of America 17/1 (1997) S. 122-44 -, gerade im zweiten Teil des Quijote zunehmend die Bedingungen der Gutenberggalaxis reflektiert, könnte sich dies zumindest teilweise auch dem Einfluss des anderen Autoren verdanken, der ihn zu einer Neukonzeption der eigenen Autorfunktion veranlassten.

54

»Für mich allein wurde Don Quijote geboren und ich für ihn; er verstand es zu handeln, ich zu schreiben; wir beide allein ergänzen einander zum Verdruß und Ärger des angeblich aus Tordesillas gebürtigen Schriftstellers, der sich erkühnt hat und sich vielleicht noch einmal erkühnen wird, die Taten meines wackeren Ritters mit seiner groben, ungeeigneten Straußenfeder zu berichten, denn dies ist keine Last für seine schwachen Schultern, noch ein Stoff für seinen eisigen Geist« (II.47, S. 1223/1312).

55

〉Früher ist natürlich in Bezug auf die Lektürechronologie zu verstehen, denn in der Genealogie der Textkomposition erfolgte die Auseinandersetzung mit Avellaneda logischerweise zu einem späten Zeitpunkt. Schon die Tatsache, dass Cervantes es nicht bei einer episodischen Auseinandersetzung belie $\beta$, sondern sein Textganzes noch einmal mit Blick auf Avellanedas Quijote überarbeitete, zeugt von der strukturellen Bedeutung des anderen Autors. Vgl. zur Problematik der Textgenese insbesondere Carlos Romero Muñoz, »Nueva lectura de El retablo de Maese Pedro«, in: Actas del I Coloquio Internacional de la Asociación de Cervantistas, Barcelona: Anthropos 1990, S. 95-130, sowie Ders., »La invención de Sansón Car- 
scheidet sie strukturell vom Autorschaftsstreit Alemáns mit Mateo Lujan keine einfache interne, von gewaltsamer Rivalität gekennzeichnete Mediation im Sinne Girards dar, sondern ist überlagert von der externen Mediation, die Cervantes mit Mateo Alemán verbindet.

Ohne im Folgenden auf inhaltliche Details und einzelne Episoden des Avellaneda-Quijote-Komplexes eingehen zu können, deren Kenntnis ich hier voraussetzen muss, will ich versuchen, mit einigen Argumenten die These zu begründen, dass Cervantes' literarische Inszenierung der eigenen Autorschaft im zweiten Teil seines Quijote nicht zuletzt der Überlagerung zweier mimetischer Konflikte zu verdanken ist.

Festzuhalten ist zunächst, dass Cervantes mit seiner grundsätzlichen Entscheidung, den Streit mit dem von Avellaneda in Umlauf gebrachten Quijote nicht nur persönlich auf der Ebene des Paratextuellen auszutragen, auf der ihn Avellaneda attackiert hatte, sondern ihn zu einem fiktionsrelevanten Element zu machen, notwendig das Modell Alemáns voraussetzen muss und sich so der Gefahr aussetzt, bei der Abwehr des direkten Rivalen selbst den anderen, in externer Mediation stärker distanzierten Rivalen zu kopieren. Die Spezifik der Autorschaftstaktiken Cervantes' im zweiten Teil des Quijote ergibt sich damit aus einer im Vergleich zu 1605 wesentlich komplizierten Ausgangslage. Die Aufgabe der Technik der eingeschobenen Novellen, die Cervantes im ersten Teil des Quijote möglicherweise nach dem Vorbild Alemáns eingesetzt hatte ${ }^{56}$ und die auch Avellaneda in seiner Fortsetzung genutzt hatte, sowie die Entscheidung, seinen Lesern den Protagonisten am Ende »tot und begraben « zu überlassen (II, S. 621/647), bilden dabei nur die auffälligsten und spektakulärsten Ergebnisse des Versuches, die Überlagerung beider Konflikte dazu zu nutzen, sich in einem Text von zwei anderen Autoren zu distanzieren.

Eine erster wesentlicher taktischer Zug Cervantes', der gleichzeitig eine Differenz zu Alemán und zu Avellaneda begründet, besteht darin, die Fortsetzung des Anderen nicht an den Punkten zu korrigieren, in denen sie vom eigenen Original abweicht, sondern gerade dort, wo sie es treu kopiert. Die Falsifikation des anderen Quijote impliziert eine Selbstfalsifikation des eigenen ersten Teils, das andere Werk wird als Gelegenheit zur Revision des eigenen Werks genutzt. Anders als Alemán, der den Gang seines Protagonisten nach

rasco«, in: Actas del II Coloquio Internacional de la Asociación de Cervantistas, Barcelona: Anthropos 1991, S. 27-69.

56 Albert A. Sicroff etwa insistierte auf der Pionierrolle Alemáns bei der Einfügung eingeschobener Novellen in eine längere Prosaerzählung, vgl. »Tres calas en el arte de interpolar cuentos: Alemán, Avellaneda y Cervantes«, in: Actas del III Coloquio Internacional de la Asociación de Cervantistas, Barcelona: Anthropos 1993, S. 473-485, Zitat S. 474). Die Taktik der Selbstrevision, mit der Cervantes auf den doppelten mimetischen Autorschaftskonflikt reagiert, würde so das Fehlen der eingeschobenen Novellen im 2. Teil des Quijote plausibel machen, die etwa Friedrich Schlegel so nachhaltig vermisste, dass er noch auf ihren Fund hoffte: »Vielleicht lassen sich die Novelas auffinden, die in den II Don Quixote sollten. Die im Iten sind die kühnsten, hellsten, dunkelsten, schönsten« (Kritische Schriften und Fragmente, Bd. V, Fragment 185, S. 253). 
Genua in der Segunda Parte ausdrücklich im paratextuellen Vorraum als Korrektur eines Versäumnisses Mateo Lujans begründete, stellt Don Quijotes Gang nach Barcelona als neuem Ziel, das Zaragoza ersetzt, eine Korrektur der Fortsetzung dar, die zugleich die Gültigkeit des im ersten Teil angekündigten und im zweiten einleitend zunächst noch einmal bestätigten Itinerars aufhebt. ${ }^{57}$ Die auktoriale Rivalität, die Cervantes auf paratextueller Ebene mit größter Heftigkeit austrägt, wird dabei anders als im Falle Alemáns nicht direkt in die binnenfiktionale Handlungsebene verlängert.

Während Alemáns Guzmán durch sein Handeln die Intentionalität seines Autors beglaubigt und diese gegen den Rivalen durchsetzt, durchkreuzt Don Quijote mit der Änderung seiner Reiseroute, die als seine eigene souveräne Willensentscheidung inszeniert wird, nicht nur die Vorschrift des anderen Autors, sondern auch das bisher als gültig vorausgesetzte auktoriale Programm Cervantes'. Sanchos Verhalten zielt in die gleiche Richtung, wenn er darauf insistiert, seine Frau heiße »Teresa Panza«, während sie bei Avellaneda durchgängig »Mari Gutiérrez« genannt wird, in logischer Konsequenz der im >originalen $<$ Quijote von 1605 praktizierten Namensgebung. ${ }^{58}$ Teresas neuer Name ist eine für jeden Leser des Quijote zu diesem Zeitpunkt unerwartete Neuigkeit, die erneut eine Falsifikation der Gültigkeit der Informationen des ersten Teils impliziert. Der Versuch zur Falsifizierung des anderen Quijote gipfelt dann in der Begegnung mit Álvaro Tarfe, der von Avellaneda neu eingeführten Figur eines Adeligen, die paradigmatisch für die Tendenz des pseudonymen Autors steht, der Komik des Don Quijote eine andere soziale Funktion zu verleihen, die sich an den Wünschen und Bedürfnissen der Adelsklasse ausrichtet. Während bei Alemán die autorschaftliche Rivalität durch entsprechende Stellvertreterfiguren im Inneren der Fiktion agonal-gewaltförmig ausagiert wurde und die Überlegenheit des eigentlichen Guzmán über sein uneigentlich-inferiores Doppel erzählerisch bekräftigt werden sollte, generiert Cervantes statt dessen eine paradoxe binnenfiktionale Instanz, die durch ihr Urteil die Differenz von >Originalく und 〉Kopieく quasi-juristisch festlegen soll, dabei aber die logischen Voraussetzungen eines solchen Urteils nicht mitbringt, da sie selbst gerade nicht neutral ist, sondern als ein in die >wahre Fiktion hineinkopierter Teil der >falschen< selbst die kategoriale Unterscheidung zwischen Wahrheit und Lüge auflöst. Als Gestalt, die aus der unwahren

57 »solo la fama ha guardado, en las memorias de la Mancha, que don Quijote la tercera vez que salió de su casa fue a Zaragoza, donde se halló en unas famosas justas que en aquella cuidad se hicieron« (Don Quijote, I.52, S. 591/634: »Nur der Ruhm hat im Gedächtnis der Leute in der Mancha die Erinnerung daran bewahrt, daß Don Quijote sich, als er zum dritten Male auszog, nach Zaragoza hin wendete, wo er den berühmten Stechen beigewohnt haben soll, die man in jener Stadt veranstaltete«.) Zaragoza wird dann noch einmal beim Aufbruch zur tercera salida als Zielort festgelegt (II.4, S. 659/680).

58 Dort heißt Sanchos Frau wechselweise »Juana Gutiérrez« und »Marí Gutiérrez« (Kap. I.7) bzw. »Juana Panza« (Kap. I.52), woraus sich logisch die komplette Namensform María Juana Gutiérrez (de) Pansa ergibt, wie Romero Muñoz, «Nueva lectura de El retablo de Maese Pedro«, S. 115, bemerkt. 
Fiktion Avellandas stammt, kann Álvaro de Tarfe schon logisch nicht deren Unwahrheit akkreditieren, weshalb er folgerichtig auch eine formal paradoxe Aussage abgibt:

Eso haré yo de muy buena gana - respondió don Álvaro - , puesto que cause admiración ver dos don Quijotes y dos Sanchos a un mismo tiempo, tan conformes en los nombres como diferentes en las acciones; y vuelvo a decir y me afirmo que no he visto lo que he visto, ni ha pasado por mí lo que ha pasado. ${ }^{59}$

Juristisch wäre eine solche Zeugenaussage, die gleichzeitig die Gültigkeit und die Ungültigkeit des Erlebten behauptet, nicht zu gebrauchen und der Erzähler geht in seinem Kommentar deshalb auch auf ironische Distanz zum Nutzen einer derartigen Beweisführung, wenn er anlässlich der Freude der Protagonisten über die Verbriefung ihrer Nicht-Identität mit den Helden Avellanedas kommentiert: »como si les importara mucho semejante declaración y no mostrara claro la diferencia de los dos don Quijotes y la de los dos Sanchos sus obras y sus palabras « ${ }^{60} \mathrm{Im}$ Rahmen des doppelten Autorschaftskonflikts, den Cervantes in seinem zweiten Teil des Quijote austrägt, ist die ironische Funktion dieses merkwürdigen Zusammentreffens mit einem Wesen aus der Parallelwelt der anderen Fiktion klar: sie macht die von Alemán vorgegebene direkte Konfrontation mit der anderen Fiktion, mit der der >originale < vom >falschen` Guzmán getrennt werden sollte, lächerlich und rückt dabei zugleich Don Alvaro, der bei Avellaneda als neue Handlungsfigur eingeführt wurde und als durchaus positiver Träger adeliger Werte gestaltet ist, in ein komisches Licht. Statt den anderen Autor als schlechten Kopisten zu denunzieren, kopiert er selbst dessen wesentlichste Neuerung in die eigene Fiktion und macht sie zu einer im Rahmen der Handlungslogik absurd-überflüssigen Gestalt. Denn nicht Treue oder Abweichung von einem ursprünglichen intentionalen Programm entscheiden für Cervantes über den Wert seiner eigenen Fortsetzung, sondern die Attraktivität der damit geschaffenen erzählten Welt und ihrer

59 II.72, S. 1207/1295: ») Das will ich gerne tun<, erwiderte Don Alvaro, >obschon es erstaunlich ist, wenn zwei Don Quijote und zwei Sancho zu gleicher Zeit existieren, die ebensosehr in den Namen übereinstimmen, wie sie sich in ihrem Verhalten unterscheiden; ich wiederhole und bestätige darum, daß ich nicht gesehen habe, was ich gesehen, noch erlebt habe, was ich erlebte. « Eine eindeutige Affirmation der Unwahrheit der Fiktion Avellanedas liefe auf das bekannte Lügner- bzw. Kreter-Paradox hinaus, wie Maurice Molho meint (»Le sujet apocryphe«, S. 44). Alvaro Tarfes Aussage wird allerdings nicht erst paradox, wenn man den Aussageinhalt mit der logischen Vorbedingung der Aussage zusammendenkt, sondern ist schon an sich paradox formuliert. Alvaro Tarfe gehört zwei möglichen Fiktionswelten an (dem Roman Avellanedas und dem Cervantes), die als alternative Texte gleichzeitig in der realen Welt des Lesers vorhanden sind. Weil er selbst aber kein Leser, sondern Bewohner dieser beiden Welten ist, kann er keine von ihnen bezweifeln, ohne sich mit diesem Zweifel selbst zu implizieren. Von daher erklärt sich auch die selbstreflexive Form der Aussage Tarfes (»me afirmo«, »ha pasado por mí«).

${ }^{60}$ II.72, S. 1208/1296: »als wäre eine solche Erklärung für sie irgendwie von Bedeutung und als hätte sich nicht schon an Worten und Werken jener Unterschied deutlich genug erwiesen, der den einen Don Quijote vom andern und den einen Sancho von jenem zweiten trennte«. 
Protagonisten, die zu durchaus eigenwilligen Charakteren ausgestaltet werden und eben keine »presonajes« im Dienste einer señorialen Adelsideologie bleiben. ${ }^{61}$

Wenn die Einführung Don Alvaro Tarfes sich so als eine bewusste ironische Abkehr von einer direkten literarischen mise en scène eines mimetischen Autorschaftskonfliktes verstehen lässt, scheint eine andere Figur genau diese Funktion zu übernehmen: Ginés de Pasamonte bzw. »Ginesillo de Parapillo« oder auch »don hjio de la puta [Herr Hurensohn], don Ginesillo de Paropillo«, wie ihn Don Quijote in einem Wutanfall nennt. ${ }^{62}$ Er tauchte schon im ersten Teil des Quijote als Galeerensträfling und Verfasser einer Autobiographie auf (I.21), um im zweiten Teil in der Verkleidung des Puppenspielers Maese Pedro (II.25-27) wiederzukehren. Zwischen diesen beiden Rollen liegt noch eine dritte, auf die es mir im Folgenden besonders ankommen wird, die des Diebes, der Sanchos Esel entwendet. Galeerensträfling und Autobiograph, Dieb und Meister trügerischer Illusionstechniken: Es kann kaum einen Zweifel geben, dass Ginés de Pasamonte im Stile eines Pícaros und Tricksters auftritt. Damit folgt er aber eindeutig dem literarischen Figurenmodell, das Alemán im Guzmán de Alfarache vorgegeben hatte und gegen seinen eigenen Konkurrenten noch einmal erfolgreich profilieren konnte. Die autobiographisch ausgerichtete Forschung, die sich seit nunmehr fast 400 Jahren um eine eindeutige Identifizierung der Autorschaft Avellanedas bemüht, hat sich seit der Studie Martín de Riquers inzwischen weitgehend darauf geeinigt, Gines de Pasamonte als ein Autorenpseudonym zu verstehen und den Verfasser des Quijote von 1614 mit dem Autobiographen der Vida y trabajos de Gerónimo de Passamonte gleichzusetzen. ${ }^{63}$ Vor lauter Begeisterung über die vermeintliche Lösung des >Rätsels` um den realen Verfasser, der hinter dem Pseudonym Avellaneda steckt, wurde dabei weitgehend vergessen, die literarisch-erzähle-

61 II.3, S. 650/672: »Y de mí - dijo Sancho -, que también dicen que soy yo uno de los principales presonajes della. - Personajes que no presonajes, Sancho amigo - dijo Sansón.« Bereits in diesem komischen, nicht wirklich adäquat übersetzbaren Versprecher von Sancho darf man wohl eine Kritik an Avellaneda sehen, der den Diener des Junkers ganz auf seine Funktion als Verlachfigur reduzierte und ihn am Ende seines Quijote zum Clown am Hofe des adeligen Archipámpanos werden lässt (vgl. Fernández de Avellaneda, El ingenioso hidalgo, S. 704). Die ideologischen Differenzen zwischen Avellaneda und Cervantes arbeitete vor allem Stephen Gilman heraus: Cervantes y Avellaneda: estudio de una imitación, México: Colegio de México 1951; James Iffland kritisiert Gilmans seiner Ansicht nach allzu simple Opposition zwischen einem vermeintlich renaissantistischen Weltbild Cervantes und einer gegenreformatorisch-barrocken Ideologie Avellanedas und begreift beide Texte als komische Unterhaltungsliteratur mit jeweils unterschiedlichen sozialen Funktionalisierungen des Komischen (De fiestas y aguafiestas: risa, locura e ideología en Cervantes y Avellaneda, Madrid/Frankfurt a. Main: Vervuert 1999).

62 Vgl. I.22, S. $247 \mathrm{ff} . / 236 \mathrm{ff}$. Im zweiten Teil wird diese Szene noch einmal erinnert, allerdings nicht die entehrende Namensverzerrung Don Quijotes erwähnt (II.27, S. 855/891).

63 Vgl. dazu die in Anm. 14 genannte Literatur, sowie die Beiträge von Helena Percas de Ponseti, »Un misterio dilucidado: Pasamonte fue Avellaneda«, in: Cervantes. Bulletin of the Cervantes Society of America 22 (2002), S. 127-154, sowie »Cervantes y Lope de Vega: postrimerías de un duelo literario y una hipótesis«, in: Cervantes 23 (2003), S. 63-115. 
rische Funktion der Pasamonte-Figur zu klären. Ohne die trotz mancher Ungeklärtheiten insgesamt nicht unplausible Identifizierung Pasamontes mit Avellanedas grundsätzlich in Frage stellen zu wollen ${ }^{64}$, möchte ich doch darauf insistieren, dass die Tatsache, dass Cervantes anders als Mateo Alemán, der seine Sayavedra-Figur auch das Pseudonym Mateo Lujans entschlüsseln lässt, das Pseudonym seines Konkurrenten nicht eindeutig lüftet, einen guten Grund hat. Nur so nämlich, ohne eine eindeutige Identifizierung des Identitätsschwindlers Ginés lässt sich die Figur dazu nutzen, den Autorschaftskonflikt mit Avellaneda mit dem gegen Alemán zu überblenden. Denn anders als die Kenntnis der unveröffentlichten und in Manuskriptform bestenfalls einem sehr kleinen Kreis von Eingeweihten bekannte autobiographische Vida des Jerónimo de Pasamonte, konnte Cervantes die Kenntnis der pseudoautobiographischen Vida des Guzmán de Alfarache bei seinen Lesern sicher voraussetzen und fest damit rechnen, dass sie dessen Roman erinnerten, wenn er seinen Ginés verkünden lässt, seine Lebensgeschichte werde »Lazarillo de Tormes und alle Bücher, die in der Gattung geschrieben worden sind oder geschrieben werden sollten «, in den Schatten stellen (I.22, S. 243/237).

Die literarische Funktionalisierung der Pasamonte-Figur geht schon deshalb nicht in einer bloß autobiographisch motivierten Abrechnung mit dem pseudonymen Autor auf, weil sie mit einer Fama verbunden ist, die dem eher unglücklichen und sich von aller Welt verfolgt fühlenden Soldaten Pasamonte einfach nicht zukam, wohl aber Alemáns Protagonisten, der genau um diesen Ruhm mit seinem >falschen< Doppel gerungen hatte. Schon beim ersten Auftritt wird Ginés vom Wächter als der »famoso Ginés de Pasamonte« (I.22, S. 241f./236) vorgestellt, ein Attribut, das in der zweiten Auflage des Quijote von 1605, in dem Ginés als Räuber eingeführt wird, der für das in der editio princeps rätselhaft bleibende plötzliche Verschwinden von Sanchos Grautier verantwortlich ist, beibehalten wird, wenn von "Ginés de Pasamonte, el famoso embustero y ladrón « (»Ginés de Pasamonte, dem berühmten Betrüger und Dieb «) die Rede ist. ${ }^{65}$ Das stellt sicher mehr als nur nur eine aus persönlichem Ressentiment heraus motvierte Beleidigung gegen einen völlig unbekannten Memoirenschreiber dar, sondern ist sicher (auch) als eine deutliche Spitze gegen Guzmáns Prätentionen auf den Ehrentitel als »ladrón famosísimo « gedacht. Der Quijote von 1615 treibt die Ironie noch weiter: nachdem der berühmte literarische Pícaro des Kollegen zunächst dazu erniedrigt wurde, für einen letztlich vom Autor Cervantes zu verantwortenden Druckfehler einzustehen $^{66}$, wird ihm gar noch sein Status als literarisches Paradigma des Gau-

64 Die größte Ungeklärtheit besteht dabei nach wie vor darin, wie die doch sehr auffällige stilistische Kluft, die zwischen der Vida und dem erzählerisch ungleich elaborierteren Quijote von 1614 klafft, erklärt werden könne.

${ }^{65}$ Vgl. die Dokumentation des eingefügten Textteils in der spanischen Werkausgabe: Don Quijote de la Mancha, Appendix, S. 1231.

${ }^{66}$ Zur Diskussion um das >Verschwinden des Esels vgl. den Kommentar Ricos an entsprechender Stelle (Don Quijote, S. 250f., Fußnote 18). Rico geht in seiner Argumentation davon aus, 
ners streitig gemacht, wenn in Sanchos Bericht über den Raub die Fama auf »jenen berühmte[n] Dieb namens Brunelo« (II. 4, S. 656/678) übergegangen ist und Ginés de Pasamonte damit als ein keineswegs origineller kleiner Betrüger dasteht.

Cervantes gestaltet seinen Ginés so nicht nur als eine komplexe Tricksterfigur, deren identitäre Uneindeutigkeit es ermöglicht, sie sowohl als Refiguration eines rivalisierenden literarischen Modells (Guzmán) als auch als Refiguration eines historischen Autorrivalen (Géronimo de Passamonte) zu lesen; indem er sie zusätzlich mit einem Druckfehler assoziiert, überschreitet er die Ebene des mimetischen Konflikts und schreibt seinem Text auch die medienhistorische Dimension der Autorschaftsproblematik ein, die bereits im zweiten Abschnitt dieses Aufsatzes ausgeführt wurde. Die Gestalt Pasamontes wird zu einer durchaus unheimlichen, unberechenbaren und immer wieder unerwartet auftauchenden Größe, deren Unheimlichkeit sich aus dem komplexen Rivalitätsverhältnis gegenüber den beiden anderen Autoren speist, aber auch aus den negativen Erfahrungen, die ein noch weitgehend der oralen Erzählkultur verpflichteter Autor mit der noch verhältnismäßig neuen Drucktechnik machen musste. Cervantes belässt es dabei nicht lediglich beim etwas unehrlichen Versuch, den Druckern die Schuld an einem Fehler anzulasten, der von Cervantes-Kritikern natürlich der »Gedächtnisschwäche des Verfassers« zugeschrieben worden war (II.27, S. 855/891). Noch vor der geschilderten paradoxalen Begegnung mit der Figur aus der anderen Fiktion (Álvaro Tarfe) konfrontiert der Verfasser seinen Helden am neuen Destinationsort Barcelona auf einer ganz materiellen Ebene mit der Fiktion des anderen, auf der ihrer technischen Genese im Buchdruck. In der Druckerei, die Don Quijote betritt, wird gerade eine neue Auflage des >falschen druckt, was Don Quijote zu einem Ausfall gegen den Autorrivalen veranlasst, dessen Buch als völlig wertlos getadelt und der selbst als »Schwein« beschimpft wird (II.62, 1146/1224f.). Nicht weniger aufschlussreich ist aber auch die Begegnung mit einem anderen autor, der eine literarische Übersetzung auf eigene Kosten drucken lässt. Er ist also Autor, Übersetzer und Drucker in einem, eine Bündelung von Autorschaftsfunktionen, die wie schon erwähnt auch Mateo Alemán kennzeichnete. Das Bekenntnis dieses Autors, seine Bücher nicht allein des Ruhmes wegen, sondern auch um des 》Gewinns « willen zu drucken, verstärkt diese Assoziation noch und lässt an den moralisch-lehrhaften Mehrwert denken, den Alemán unter Verwendung des gleichen Terminus - »provecho« - für seinen Guzmán reklamiert hatte. ${ }^{67}$ Un-

dass Cervantes selbst zu nachlässig bei der Einfügung der entsprechenden Textstelle in der Zweitauflage des Textes war, wodurch erneute textuelle Inkohärenzen entstanden. Dass damit tatsächlich das viel diskutierte Problem des verschwundenen Esels geklärt ist, wie Ricardo Senabre meint (Don Quijote de la Mancha, II, S. 122), darf dagegen bezweifelt werden.

67 »yo no imprimo mis libros para alcanzar fama en el mundo, que ya en él soy conocido por mis obras: provecho quiero, que sin él no vale un cuatrín la buena fama«. Rothbauers Über- 
abhängig davon, als wen man sich den Autor in der Druckerei von Barcelona konkret vorstellen möchte, zeugt die Szene von einer gewissen Skepsis der >neuen< Technik gegenüber. Wenn Don Quijote fürchtet, die Last von »dos mil cuerpos«, d. h. 2.000 Buch-Körpern, werde den menschlichen Körper des Verfassers möglicherweise noch erdrücken (falls sie sich als unverkäuflich erwiesen), zeigt sich auch ein Stück von der Wehmut eines Autors, welcher der Präsenz des Körpers in der Schrift, wie sie in der Tradition oraler Erzählkultur noch gewährleistet war, durchaus nachtrauerte, wie vor allem die Studie Michel Moners gezeigt hat. ${ }^{68}$ Einer der großen Vorteile dieser Tradition, den Cervantes gerade im Fall des fehlenden Esels ausspielt, lag in der Fähigkeit zur Improvisation in unmittelbarer Interaktion mit dem Publikum und zur funktionalen Integration von Ereignishaftem in die erzählerische Welt. Für einen Autor wie Alemán, der viel stärker auf die Gestalt des gedruckten Textes fixiert war, hätten die textuellen Inkohärenzen, welche die editio princeps des Romans von Cervantes durchziehen, einen schwerwiegenden Fehler dargestellt, den es möglichst rasch in einer weiteren Auflage zu korrigieren galt. Cervantes dagegen macht aus dem Druckfehler einen erzählerischen Gewinn. Über die Leserfigur des salmantinischen Bakkalaureus Sansón Carrasco, der auf das rätselhafte Verschwinden des Esels aufmerksam macht, macht er sein eigenes >technisch/-mediales Versagen zum Bestandteil einer mise en abyme des ersten Teiles, der ins Innere des zweiten Teils gespiegelt wird. ${ }^{69}$

Die selbstreflexive Wendung, die der Don Quijote damit bekommt und die nach genieästhetischem Verständnis als Zeichen seines unendlich tiefen Genies gilt, stellt aus editionsphilologischer Sicht einen Rückschritt zum Fehlerhaften dar, denn alle textuellen Emendationen, die zwischen der editio princeps und späteren Auflagen der primera parte stattgefunden haben, werden nun ausdrücklich aus dem Vorwissen des Lesers, das mit Sansón Carrasco zu einer Vorraussetzung des weiteren Erzählens geworden ist, ausgeschlossen. Cervantes autorisiert so die editorisch schwächste aller möglichen Druckvarianten des Don Quijote von 1605. ${ }^{70}$ Dank seiner Entscheidung, den zweiten Don Quijote als Selbstrevision des ersten anzulegen und die erzählerische Identität seiner Helden von der Bindung an ein versprochenes auktoriales Erzählprogramm zu befreien, kann er nun souverän von früheren Fehlern profitieren. Die Stärkung seiner Autorschaft gegen die anderen, auf möglichst einheitlichen Schriftsinn festgelegten Autoren geht im zweiten Teil so paradoxerweise auch aus seiner mangelnden Fähigkeit zur Fixierung des gedruckten

setzung vereindeutigt den »provecho« an dieser Stelle zum rein materiellen »Verdienst« (II.62, S. 1145/1124).

- Ecrits et paroles, Madrid: Casa de Velázquez 1989.

${ }^{69}$ Weshalb Cervantes' Text auch als ein klassisches Beispiel eines récit spéculaire gilt. Vgl. Lucien Dällenbach, Le récit spéculaire, Paris: Seuil 1977, S. 115-118.

70 Im Gespräch zwischen Don Qujiote und Sansón Carrasco wird auch ausdrücklich die Editionsgeschichte des ersten Teils und seine unterschiedlichen Auflagen angesprochen. Vgl. II.3, S. $647 / 669$. 
Textes hervor. Diese Paradoxie bereitet noch heute jeder Textkritik Probleme, die auf die Kanonisierung eines möglichst kohärent lesbaren Don Quijote ausgerichtet ist. ${ }^{71}$ Und für eine subjektkritisch ausgerichtete Theorie des Automedialen sollte sie nicht belanglos sein, zeigt sie doch, dass die Stärke und individuelle Unverwechselbarkeit von Autorschaft gerade aus dem Verzicht auf autogenetische Selbstschließung hervorgehen kann, aus der produktiven Einbeziehung der Instanz des (bzw. der) als Mediatoren wirkenden anderen Autoren und aus einem taktisch geschickten Umgang mit dem technischen Medium des Buchdrucks, dessen Mechanismen Cervantes anders als Alemán nicht zu kontrollieren versuchte, sondern in eine Autorschaftsposition aufnahm, die ihr intentionales Schreibprogramm flexibel und anpassungsfähig hält. So ist die Vollendung, die der Roman Don Quijote erreicht, wenn er seinen Helden als Identifikationsfigur definitiv opfert und damit einer potentiell unendlichen Lust zum Weitererzählen (und Lesen) den Boden entzieht, weniger der Autonomie des Genies Cervantes' geschuldet als dessen Fähigkeit zu einer >schwachen Autorschaft, zum Einlass der Schrift des Anderen ins eigene Werk.

71 Francisco Ricos Kritik an der Fetischisierung der editio princeps, die in der Cervantes-Philologie lange Zeit geherrscht habe und aufzugeben sei zugunsten der Erstellung eines logischkohärent lesbaren Textes, der seinen Lesern »pasatiempo y gusto« des Leser ermögliche (vgl. Rico in der Einleitung zum Don Quijote, S. CCXXXV ff.), ist sicher nicht unbegründet, seine editorische Zielsetzung hat jedoch den entscheidenden Nachteil, dass dabei der in den Text ausdrücklich eingeschriebene Wille des Autors, seinen Lesern gerade solche Inkohärenzen zuzumuten, ignoriert werden muss. Nähme man Cervantes' starke Prägung durch die Oralkultur und seine Nachlässigkeit gegenüber den Anforderungen des Buchdrucks ernst, müsste man folgerichtig auf die editionskritische Fixierung einer einheitlichen Textgestalt verzichten und den Weg der critique génétique gehen, die gerade den prozessualen Charakter der Textherstellung sichtbar macht. 